\title{
Leverage points for sustainability transformations: nine guiding questions for sustainability science and practice
}

\author{
Julia Leventon ${ }^{1}\left(\mathbb{D} \cdot\right.$ Dave J. Abson $^{2} \cdot$ Daniel J. Lang $^{2}$
}

Received: 4 March 2021 / Accepted: 15 April 2021

○) Springer Japan KK, part of Springer Nature 2021 corrected publication 2021

\begin{abstract}
The concept of leverage points offers great potential to consider how we can intervene in systems to create transformations for sustainability. In this special issue, we draw together a diverse collection of research that engages with this central idea. The papers cover three broad topics: (1) the use of a 'leverage points lens' for systems framings and understandings; (2) how individual interventions can be understood and critiqued from a leverage points perspective; and (3) the implications of a leverage points approach for research practice and action. Across these topics, we present the papers, and embed them within current critical debate in sustainability science. In doing so, we produce nine guiding questions to shape the research and practice of leverage points for sustainability transformation. These nine questions introduce conceptual clarity to untangle some of the deeper questions around which system we are engaging with, whose system counts, and whose sustainability we are seeking to create. They further shape how we deliver a leverage points research practice. We intend, therefore, that our guiding questions open up exploration across systems and worldviews, and help us to dance with systems.
\end{abstract}

Keywords Sustainability science $\cdot$ Transdisciplinarity $\cdot$ Systems thinking

\section{Introduction}

Donella Meadows' notion of leverage points has much to contribute to sustainability science. It was first offered as a metaphor and heuristic framework for conceptualizing the potential of different interventions in complex systems to generate systemic change (Meadows 1999). The basic premise is that greater change is created by pushing on the deeper system properties, such as the rules or the paradigms that shape the system, in comparison to shallower properties such as material flows or reward structures. It complements calls from many quarters for fundamental systems change

Handled by Osamu Saito, Institute for Global Environmental Strategies, Japan.

Julia Leventon

leventon.j@czechglobe.cz

1 Global Change Research Institute of the Czech Academy of Sciences CzechGlobe, Bělidla 986/4a, 60300 Brno, Czech Republic

2 Faculty of Sustainability, Leuphana University of Lüneburg, Universitätsallee 1, 21335 Lüneburg, Germany
(e.g.,Dovers and Handmer 1992; Fischer et al. 2007). There have long been calls for a move away from neoliberal paradigms, rather than just adjusting policies and or resource allocation within our existing economy (Göpel 2016); for degrowth, rather than a continued pursuit of increasing GDP (Kallis 2018); and for recognizing that continued growth is not linked to increasing human well-being (Steinberger et al. 2020). The leverage points concept holds the promise of complementing such critiques by adding a systems-based, change-oriented perspective. It is of particular relevance in understanding and designing interventions for sustainability transformations (Abson et al. 2017). Thus, it promises to offer insight into thinking about how we transform systems.

Research into leverage points for sustainability transformation has begun to gain traction and importance in sustainability science. There is emerging place-based work that seeks to critique system interventions in terms of the points they target, and explore their interactions (Tourangeau and Sherren 2020; Manlosa et al. 2019). This application of leverage points as a way to critique interventions fits to Meadows' original intention in articulating the framework. It is important work, supported by calls for deeper interventions in systems to achieve biodiversity and climate change 
outcomes, and to highlight the kinds of actions that these interventions, or levers, would entail (Díaz et al. 2019; Proust et al. 2012). But, there is additional power in the framework as a boundary object (Star and Griesemer 1989) for bringing different disciplines and stakeholders together (Fischer and Riechers 2019; Abson et al. 2017). In doing so, the concept is stretched, reshaped, and expanded to offer new insights into systems change. As this happens, it is useful to take stock, reflect, and consider what these various directions offer in understanding, and actively contributing to, systems change.

In this special issue, we seek to offer such reflection by bringing together a collection of research that works with the leverage points concept in a variety of ways. The papers were initially presented at the Leverage Points conference in February 2019, at Leupana University of Lüneburg in Germany. The conference brought together more than 500 researchers and practitioners to consider how the leverage points framework helps us to explore systems, navigate change, and create action (see also Leventon et al. 2019). The conference itself marked the culmination of a 5-year research project, hosted at Leuphana, on the topic of leverage points for sustainability transformation. The project engaged 20 researchers with a focus on food and energy systems; including consideration of the knowledge, the governance structures and the relationships of people to nature within these systems, and transdisciplinary case studies to ground this research in Romania (Transylvania) and Germany (Lower Saxony). We thus embed the papers of the special issue within the experiences and findings from the project and conference, and within broader literature from across sustainability science.

In this editorial, we seek to bridge these diverse contributions, and understand how these approaches all provide a piece of the jigsaw puzzle to understanding leverage points for sustainability interventions. In doing so, we consider what it means to take a leverage points perspective within sustainability science, and what are the future avenues of research and practice. It is evident through this collection that the papers do not always agree with how systems are (or should be) framed, nor use the same terminology to describe the fundamental components of the leverage points framework: the system, the lever, the leverage points, the interventions, etc. What is a leverage point for one author, is a system or an intervention for another. At times Meadows (and in fact the editors!) are critiqued as being too narrow in their systems framing to deliver fundamental systems change (e.g., Davelaar 2021). Meadows' later essay, Dancing with Systems (Meadows 2001) grapples with the complexity, uncertainty and the interconnected, multi-scale nature of systems. She calls on us to "...discover how [the system's] properties and our values can work together to bring forth something much better than could ever be produced by our will alone" (p.59). Some of the contributions here explicitly grapple with this complexity [see, for example. Davelaar (2021) and Birney (2021)]. However, we believe this collection of papers, when seen as a collection, highlights a much broader, more pluralistic framing of leverage points that helps us to dance with the systems in which we wish to see positive, transformative change.

While the papers in this special issue are very diverse, we identify three broad ways in which they contribute to the development of the leverage points concept: (1) the use of a 'leverage points lens' for systems framings and understandings; (2) how individual interventions can be understood and critiqued from a leverage points perspective; and (3) the implications of a leverage points approach for research practice and action. As we move through the contributions, we highlight a range of guiding questions that help us to navigate a broader framing to dance with systems and engage with leverage points for sustainability transformation. We conclude by highlighting how these guiding questions map out a future trajectory for leverage points research and practice.

\section{Systems framings and understandings}

The papers in this issue demonstrate the utility and coherence offered by a tightly defined systems framing as a lens to investigate systems and related interventions. Meadows' original work gave an instrumental framing of a system; it was a realist object with clear actors and connections through flows of materials and information. Closest to these framings are those papers that consider a tightly bounded system, such as a governance system (Jiren et al. 2021), a place-based social-ecological system (Schlaile et al. 2020) or city authorities (Bryant and Thomson 2020). These papers demonstrate how a leverage points framework can help us to identify the boundaries of a system, who the actors are, what the connections are, and what interventions might look like. Each of the systems being studied can be characterised around leverage points as systems properties; they all have intent/paradigms, design, processes and materials (see Abson et al. 2017) that can be unpacked and examined (e.g., Lam et al. 2020). These papers also demonstrate that we can take a multitude of disciplinary and interdisciplinary perspectives to understand and unpack these systems. For example, while Jiren et al., Lam et al., and Bryant and Thompson all examine both issues of governance and networks of actors, Jiren et al., take a new institutionalist lens with interviews and policy analysis, Lam et al. employ social network analysis, and Bryant and Thomson's approach is grounded in sociology with an ethnographic, lived experience approach. To this regard, the leverage points framework gives us a common anchor point, or boundary object to think 
across these different disciplinary perspectives (c.f. Fischer and Riechers 2019).

Many papers in this collection demonstrate the different scales of systems and their interactions. Troeger and Reese (2021) and Woiwode et al. (2021) both pick up on the duality of individuals; both as systems themselves, and as actors within broader systems. In these framings, each individual is a system, incorporating system properties of intent, design, process and materials. Davelaar refers to an onion bulb metaphor of systems, instead of the often-cited iceberg metaphor, demonstrating the nested nature of systems, whereby narrow systems (e.g., the individual) are nested with broader systems that influence them. In this regard, we can see that, for example, the focal systems of Schlaile et al. and Bryant and Thomson are embedded within (and shaped by) broader scale systems, such as knowledge and political systems. Similarly, the individual systems in Woiwode et al., are influenced by the broader spiritual or religious systems that they are part of. And in Lam et al., the individuals create collective network systems, which in turn both implement interventions, and represent interventions in the larger systems that they are part of.

This collection requires us to remain critical of the boundaries and framings of the system in focus. Stanley (2020) provides an evocative story of how single objects (in this case a cemetery) can be part of multiple systems and multiple problem framings to different people. The paper addresses how the imposition of values from one culture can erode values in another; a systems clash and its impact. These normative questions of whose system framing counts becomes an important question to ask in leverage points research. Indeed Davelaar cautions that the leverage points metaphor has become the system paradigm. Certainly numerous papers here engage tangentially with questioning whose framing counts. For example Jiren et al., touch on the issue of how formal and informal institutions differently characterise a system and interventions. Wigboldus and Jochemsen (2020) explicitly engage with these normative elements of whose system, and where should it be changing to? They offer an approach (modal aspects) to explore these issues.

Overall, the papers in this issue demonstrate the way in which systems can be framed, that framings are normative, and that different framings and scales are connected, nested and interacting. Dealing with this complexity, and indeed, dancing with these systems is no easy feat. To help those working with leverage points to position their work, understand how it fits to others, and remain sensitive to the impacts of the normative framings they introduce, we offer the following reflection questions:

1. What is the system of focus and what are its properties (paradigm, design, processes and materials)?
2. What are the problem framings and norms that underpin this system framing?

3. What systems is the focal system nested within (multiscale systems) or connected to (different system framings)?

\section{Understanding interventions for fostering transformation within the leverage points perspective}

These questions of nested and connected systems become particularly pertinent when considering interventions from a leverage points perspective. Jiren et al. outline how interventions at one leverage point have knock-on impacts at other leverage points, as the points are related and create changes over time (see also Manlosa et al. 2019). We can also see two implications highlighted by Linnér and Wibeck (2021): (1) that interventions in small (spatial) scale systems can have knock-on implications to the systems they are nested within, if they are harnessed as opportunities for learning and dialogue; and (2) interventions that work in one context-specific system, may not work elsewhere. Indeed, we need to understand how the system properties shape the successes and failures of interventions. We can add a third from Bryant and Thomson: Interventions at deeper leverage points proliferate subsequent interventions at shallower leverage points. Thus, we see that an intervention is rarely a single intervention at a single leverage point, within a single system. The knock-on impacts to other systems and system properties can be harnessed. Cuppen et al. (2020), Moreno-Cely et al. (2021), and Bryant and Thomson all point towards collaborative learning as a mechanism for such harnessing (more on this follows).

The papers here further argue that fundamental transformation of a smaller-scale system is a precondition for fundamental transformation of its connected systems. Troeger and Reese explore interventions to target system intent towards sufficiency, and find that the intervention needs to also match the normative positions of the individual actors within an overall system. Such findings position the individual person as a system themselves, and demonstrates that the individual's intents need to be considered, alongside that of the broader scale intents of the systems they are embedded, and act, within (see also Ives et al. 2020). This is a theme also picked up by Woiwode et al., discussing the role of inner transformations; both as individuals, and collectively. They thus point the role of self, and of religion and spirituality, both as ways to prompt inner reflection, and as interventions for collective change. They explore how such inner transformation leads to behaviour change (e.g., transformation of the individual as a system), and ultimately, broader system change, noting that we cannot change the intent of a system without changing the intent of the people that are 
embedded within, and perform, that system. We thus see that the transformation of the individual as a system is needed for transformation of broader systems that the individuals are part of. Indeed, the role of such spirituality in shaping our intent (individually and collectively) should be afforded similar weight as to the idea of reconnecting to nature (see e.g., Ives and Kidwell 2019).

Working to transform systems therefore requires that we are able to navigate the impact of interventions, and their consequences (intended and unintended) within and between systems, directly and indirectly. Indeed, dancing with systems means that we need to be able to respond to changing situations and embrace emerging system dynamics. To deal with this complexity, we offer the following guiding questions for interrogating interventions:

4. Which system properties (paradigm, design, processes and materials) does the intervention target, in which focal system?

5. What properties are impacted over time, or space, or via indirect impacts?

6. How does that intervention influence and work in connected or nested systems?

\section{Towards a leverage points research practice}

There is a strong focus in much of this leverage points research on transdisciplinarity and co-creating knowledge beyond researchers. There is a theme of developing solutions together as a way of learning by doing (e.g., Birney 2021, Cuppen et al., Moreno-Cely et al., Wigboldus and Jochemsen), blurring the lines between the categories of leverage points as an intervention study, and leverage points as a mode of research. Indeed, this transdisciplinary emphasis is framed as a way of both learning, and ensuring that interventions and their impact are learned from, and expanded within focal systems and beyond (cf. Linnér and Wibeck). The presented approaches bridge or dissolve the gap between practitioner and researcher (e.g., Birney) and further extend framings of transdisciplinarity by celebrating and harnessing the sense of becoming part of the system, rather than rejecting this system in search of a mythical objectivity (see e.g., Pereira et al. 2020). We note, with a sense of irony, that delivering such transformative research will often require a transformation of the academic system that many of us are nested within (O'Brien et al. 2013; Fazey et al. 2020; Caniglia et al. 2021).

Regardless of whether or not the research design is based on transdisciplinarity and co-creation, a leverage points research practice demands a level of personal transdisciplinarity. Birney highlights the key role in recognising one's own positionality within a system to understand and contextualise learning, and indeed to answer the six questions we have thus far proposed. Davelaar refers to singular transdisciplinarity, and chimes with Augsberg (2014) in her paper on 'becoming transdisciplinary'. A personal process of reflexivity and reflection pushes us to consider the assumptions and biases we introduce to the way we choose to frame our focus system, or the lens we engage with. We agree that this process is essential in leverage points research to ensure that we are indeed consciously navigating systems complexity, and understanding how our own work fits within this "onion" of systems (as described by Davelaar).

Indeed, this self-reflection brings us back to the question of problem and system framings. Stanley's work prompts reflection on how the same object is framed differently within different systems. Arguably, the cemetery in this paper is a boundary object, taking on different meanings for different systems and the people incorporated therein. Cuppen et al. harness the role of such boundary objects as the focus of their research practice. They explore a boundary object ecology, which incorporates the process of creating boundary objects, and the objects themselves. The ecology they describe of exploring world views and finding points to interact is reminiscent of the process many of us experienced in the leverage points project, and even in the creation of this special issue. It also chimes with that described by Freeth and Caniglia (2020). Within these framings, boundary objects serve to bridge worldviews, and provide objects that bring us together to find common language and perspectives. They allow us to position ourselves within multiple, nested systems and their constructions. In this way, a leverage points research practice benefits from identifying and exploring boundary objects. However it moves beyond framing leverage points themselves as the interdisciplinary boundary object (see above, noting that this is still relevant), and asks us to identify the boundary objects that sit between multiple problem and systems framings. In doing so, we have a key link in identifying connected systems and understanding their framings.

The research practice framed by this contribution is one of transdisciplinarity; this may (or may not) be a transdisciplinary research design, based on co-creation (as per Jahn et al. 2012), but it is clearly an internal, personal process. It provides space to reflect on the questions 1-6 that we outlined above. However, it also goes further and requires that we reflect on how we engage with a system, and how we can converge around the creation and understanding of boundary objects. It facilitates dancing with systems by encouraging us to embrace uncertainty, listen to what the system tells us, stay as a learner of the system, and question our role in the system (see Meadows 2001). We therefore add a further three guiding questions to shape a leverage points research practice: 
7. Where am I in the system?

8. What are the boundary objects within this system?

9. How do I act, and what normative framings do I add to this system?

\section{Conclusions: a future pathway for leverage points for sustainability transformations (learning to dance with systems)}

In this editorial, we have sought to contextualise the 13 varied and diverse contributions that all, in some way, address leverage points for sustainability transformation. Each of these papers is grounded in a different disciplinary (or interdisciplinary) approach, and each explores different systems, in different places and times. On the surface, these papers could be seen as having different definitions of the key terms present within a leverage points framework: levers, interventions, leverage points and systems are all framed differently across the papers. However, rather than see this variety as confusion, we see it as testament to the contribution that a leverage points perspective can make in understanding how to create fundamental systems change towards sustainability. We have outlined here how system boundaries are normative, scaled, nested and connected. Following this, the papers present a range of different system boundaries and framings, and begin to consider connections and relationships between systems. Thus, the interventions presented are similarly specific to the system in question, but we can start to see ways to navigate their impact across scales and systems. We have put forward our first six guiding questions that encourage those of us who engage with leverage points to reflect and be conscious of the framings we use and the consequences of these framings. These guiding questions help us to move forward, with conceptual clarity (rather than confusion) to be able to tackle some of the deeper questions around whose system counts, and whose sustainability we are seeking to create. We can begin to engage with leverage points to consider social justice and equity across different worldviews.

We also see from this collection that fulfilling this promise of leverage points demands a reflexive and reflective research practice. There is a role for disciplinary methodologies, there is a role for transdisciplinary methodologies, and there is a role for considering how they connect to each other within and across systems. This demands that those engaged in leverage points work remain personally reflexive and reflective, and willing to engage in explorations as to how their worldviews fit to those of others, within and between systems. To this end, our final three guiding questions (questions 7-9) are key in delivering a leverage points research practice. As next steps, we hope that the research and practice community can see some clarity in how they might engage with a leverage points framework, and how it might be useful to them; particularly with a broader scope of how systems are framed. And we hope that our guiding questions open up exploration across systems and worldviews, and encourage researchers and practitioners to embrace uncertainty and complexity. We hope that those engaging with leverage points move away from the steady march for certainty, and narrow systems scope, and instead use our questions to take the first, perhaps faltering, but exciting and new, steps in the multiple system dances required to create transformative change.

Acknowledgements This research was funded by the Volkswagen Stiftung and the Niedersächsisches Ministerium für Wissenschaft und Kultur, grant number A112269. We would also like to thank all the members of the Leverage Points project team for the inspiration and thoughts that helped shape our understanding and Guido Caniglia for his helpful and constructive comments on an earlier version of the manuscript. This research draws on work undertaken in a large transdisciplinary research project (Leverage Points for Sustainability Transformation). The authors acknowledge and thank all project members for their ideas and input in the early stages of this work, even where they are not listed as authors. Full details of project members and their research are available at https://leveragepoints.org

\section{References}

Abson DJ, Fischer J, Leventon J, Newig J, Schomerus T, Vilsmaier $\mathrm{U}$ et al (2017) Leverage points for sustainability transformation. Ambio 46(1):30-39. https://doi.org/10.1007/s13280-016-0800-y

Augsburg T (2014) Becoming transdisciplinary: the emergence of the transdisciplinary individual. World Futur 70(3-4):233-247. https://doi.org/10.1080/02604027.2014.934639

Birney A (2021) How do we know where there is potential to intervene and leverage impact in a changing system? The practitioners perspective. Sustain Sci. https://doi.org/10.1007/s11625-021-00956-5

Bryant J, Thomson G (2020) Learning as a key leverage point for sustainability transformations: a case study of a local government in Perth, Western Australia. Sustain Sci. https://doi.org/10.1007/ s11625-020-00808-8

Caniglia G, Luederitz C, von Wirth T, Fazey I, Martín-López B, Hondrila $\mathrm{K}$ et al (2021) A pluralistic and integrated approach to action-oriented knowledge for sustainability. Nat Sustain 4(2):93100. https://doi.org/10.1038/s41893-020-00616-z

Cuppen E, Nikolic I, Kwakkel J, Quist J (2020) Participatory multimodelling as the creation of a boundary object ecology: the case of future energy infrastructures in the Rotterdam Port Industrial Cluster. Sustain Sci. https://doi.org/10.1007/s11625-020-00873-Z

Davelaar D (2021) Transformation for sustainability: a deep leverage points approach. Sustain Sci. https://doi.org/10.1007/ s11625-020-00872-0

Díaz S, Settele J, Brondízio ES, Ngo HT, Agard J, Arneth A et al (2019) Pervasive human-driven decline of life on earth points to the need for transformative change. Science (New York). https:// doi.org/10.1126/science.aax3100

Dovers SR, Handmer JW (1992) Uncertainty, sustainability and change. Glob Environ Chang 2(4):262-276. https://doi.org/10. 1016/0959-3780(92)90044-8

Fazey I, Schäpke N, Caniglia G, Hodgson A, Kendrick I, Lyon C et al (2020) Transforming knowledge systems for life on earth: visions of future systems and how to get there. Energy Res Soc Sci 70:101724. https://doi.org/10.1016/j.erss.2020.101724 
Fischer J, Riechers M (2019) A leverage points perspective on sustainability. People Nat 1(1):115-120. https://doi.org/10.1002/pan3.13

Fischer J, Manning AD, Steffen W, Rose DB, Daniell K, Felton A et al (2007) Mind the sustainability gap. Trends Ecol Evol 22(12):621624. https://doi.org/10.1016/j.tree.2007.08.016

Freeth R, Caniglia G (2020) Learning to collaborate while collaborating: advancing interdisciplinary sustainability research. Sustain Sci 15(1):247-261. https://doi.org/10.1007/s11625-019-00701-z

Göpel M (2016) The great mindshift. How a new economic paradigm and sustainability transformations go hand in hand / Maja Göpel. Springer, Berlin

Ives CD, Kidwell J (2019) Religion and social values for sustainability. Sustain Sci 14(5):1355-1362. https://doi.org/10.1007/ s11625-019-00657-0

Ives CD, Freeth R, Fischer J (2020) Inside-out sustainability: the neglect of inner worlds. Ambio 49(1):208-217. https://doi.org/ 10.1007/s13280-019-01187-w

Jahn T, Bergmann M, Keil F (2012) Transdisciplinarity: Between mainstreaming and marginalization. Ecol Econ 79:1-10. https://doi. org/10.1016/j.ecolecon.2012.04.017

Jiren TS, Riechers M, Bergsten A et al (2021) A leverage points perspective on institutions for food security in a smallholder-dominated landscape in southwestern Ethiopia. Sustain Sci. https://doi. org/10.1007/s11625-021-00936-9

Kallis G (2018) Degrowth. 1st. Agenda Publishing, Newcastle upon (The economy/key ideas)

Lam DPM, Martín-López B, Horcea-Milcu AI, Lang DJ (2020) A leverage points perspective on social networks to understand sustainability transformations: evidence from Southern Transylvania. Sustain Sci. https://doi.org/10.1007/s11625-020-00881-z

Leventon J, Becker S, Zimmermann H, von Wehrden H (2019) Leverage Points 2019: a transdisciplinary conference, inspiring change. GAIA Ecol Perspect Sci Soc 28(1):55-57. https://doi.org/10. 14512/gaia.28.1.13

Linnér B-O, Wibeck V (2021) Drivers of sustainability transformations: leverage points, contexts and conjunctures. Sustain Sci. https://doi.org/10.1007/s11625-021-00957-4

Manlosa AO, Schultner J, Dorresteijn I, Fischer J (2019) Leverage points for improving gender equality and human well-being in a smallholder farming context. Sustain Sci 14(2):529-541. https:// doi.org/10.1007/s11625-018-0636-4

Meadows D (1999) Leverage points: places to intervene in a system. The Sustainability Institute, Hartland

Meadows D (2001) Dancing with Systems. Whole Earth 106:58-63

Moreno-Cely A, Cuajera-Nahui D, Escobar-Vasquez CG et al (2021) Breaking monologues in collaborative research: bridging knowledge systems through a listening-based dialogue of wisdom approach. Sustain Sci. https://doi.org/10.1007/ s11625-021-00937-8

O'Brien K, Reams J, Caspari A, Dugmore A, Faghihimani M, Fazey I et al (2013) You say you want a revolution? Transforming education and capacity building in response to global change. Environ Sci Policy 28:48-59. https://doi.org/10.1016/j.envsci.2012.11.011

Pereira L, Frantzeskaki N, Hebinck A, Charli-Joseph L, Drimie S, Dyer $M$ et al (2020) Transformative spaces in the making: key lessons from nine cases in the Global South. Sustain Sci 15(1):161-178. https://doi.org/10.1007/s11625-019-00749-x

Proust K, Newell B, Brown H, Capon A, Browne C, Burton A et al (2012) Human health and climate change: leverage points for adaptation in urban environments. Int J Environ Res Public Health 9(6):2134-2158. https://doi.org/10.3390/ijerph9062134

Schlaile MP, Urmetzer S, Ehrenberger MB, Brewer J (2020) Systems entrepreneurship: a conceptual substantiation of a novel entrepreneurial "species." Sustain Sci. https://doi.org/10.1007/ s11625-020-00850-6

Stanley JL (2020) Revising Reykjavík: changing narratives of skeletons, structures, and imagined futures. Sustain Sci. https://doi. org/10.1007/s11625-020-00817-7

Star SL, Griesemer JR (1989) Institutional ecology, translations and boundary objects: amateurs and professionals in Berkeley's Museum of Vertebrate Zoology, 1907-39. Soc Stud Sci 19(3):387-420. https://doi.org/10.1177/030631289019003001

Steinberger JK, Lamb WF, Sakai M (2020) Your money or your life? The carbon-development paradox. Environ Res Lett 15(4):44016. https://doi.org/10.1088/1748-9326/ab7461

Tourangeau W, Sherren K (2020) Leverage points for sustainable wool production in the Falkland Islands. J Rural Stud 74:22-33. https:// doi.org/10.1016/j.jrurstud.2019.11.008

Tröger J, Reese G (2021) Talkin' bout a revolution: an expert interview study exploring barriers and keys to engender change towards societal sufficiency orientation. Sustain Sci. https://doi.org/10. 1007/s11625-020-00871-1

Wigboldus S, Jochemsen H (2020) Towards an integral perspective on leveraging sustainability transformations using the theory of modal aspects. Sustain Sci. https://doi.org/10.1007/ s11625-020-00851-5

Woiwode C, Schäpke N, Bina O, Veciana S, Kunze I, Parodi O et al (2021) Inner transformation to sustainability as a deep leverage point: fostering new avenues for change through dialogue and reflection. Sustain Sci. https://doi.org/10.1007/ s11625-020-00882-y

Publisher's Note Springer Nature remains neutral with regard to jurisdictional claims in published maps and institutional affiliations. 